\title{
Evolution of the hydrogen-bonding motif in the melamine-cyanuric acid co-crystal: a topological study
}

\author{
Andre N. Petelski ${ }^{1,3}$ • Nelida M. Peruchena ${ }^{2,3}$. Gladis L. Sosa ${ }^{1,3}$
}

Received: 10 June 2016 / Accepted: 10 July 2016

(C) Springer-Verlag Berlin Heidelberg 2016

\begin{abstract}
The melamine (M)/cyanuric acid (CA) supramolecular system is perhaps one of the most exploited in the field of self-assembly because of the high complementarity of the components. However, it is necessary to investigate further the factors involved in the assembly process. In this study, we analyzed a set of $13 \mathrm{M}_{n} / \mathrm{CA}_{m}$ clusters (with $n, m=1,2$, 3 ), taken from crystallographic data, to characterize the nature of the hydrogen bonds involved in the self-assembly of these components as well as to provide greater understanding of the phenomenon. The calculations were performed at the B3LYP/ $6-311++\mathrm{G}(\mathrm{d}, \mathrm{p})$ and $\omega-\mathrm{B} 97 \mathrm{XD}$ (single point) levels of theory, and the interactions were analyzed within the framework of the quantum theory of atoms in molecules and by means of molecular electrostatic potential maps. Our results show that the stablest structure is the rosette-type motif and the aggregation mechanism is governed by a combination of cooperative and anticooperative effects. Our topological results
\end{abstract}

Electronic supplementary material The online version of this article (doi:10.1007/s00894-016-3070-5) contains supplementary material, which is available to authorized users.

Gladis L. Sosa

glsosa@frre.utn.edu.ar; http://www.frre.utn.edu.ar/quitex

1 Grupo UTN de Investigación en Química Teórica y Experimental (QUITEX), Departamento de Ingeniería Química, Facultad Regional Resistencia, Universidad Tecnológica Nacional, French 414, H3500CHJ Resistencia, Chaco, Argentina

2 Laboratorio de Estructura Molecular y Propiedades (LEMYP), Área de Química Física, Facultad de Ciencias Exactas y Naturales y Agrimensura, Universidad Nacional del Nordeste, Avenida Libertad 5460, 3400 Corrientes, Argentina

3 Instituto de Química Básica y Aplicada del Nordeste Argentino (IQUIBA-NEA), Universidad Nacional del Nordeste-Consejo Nacional de Investigaciones Científicas y Técnicas, Avenida Libertad 5460, 3400 Corrientes, Argentina explain the polymorphism in the self-assembly of coadsorbed monolayers of $\mathrm{M}$ and $\mathrm{CA}$.

Keywords Supramolecular · Self-assembly · Rosette motif · Hydrogen bonds $\cdot$ Negative cooperativity

\section{Introduction}

Molecular self-assembly is one of the fundamental concepts of supramolecular chemistry. It can be defined as the spontaneous noncovalent association of two or more molecules from equilibrium conditions to stable aggregates with well-defined composition and structure $[1,2]$. This spontaneity implies information that involves the organization of functional structures [3] arranged by multiple binding with positive or negative cooperativity [4]. The current research activity is focused on controlling self-organization at the molecular level [5] and thus producing a new generation of materials $[6,7]$. One of the systems that have monopolized the major interest in this field, and one of the most exploited ones, is the melamine (M)/ cyanuric acid (CA) mixture. Many investigations have taken advantage of these compounds to obtain structures such as polymeric rods [8], molecular boxes [1, 9], supramolecular membranes [10,11], and photoresponsive materials [12]. This system has opened up a great stream of experimental and theoretical research and applications, and remains the subject of intense scientific activity.

The first crystal structure of M/CA was reported by Wang et al. [13] in 1990, although the structure was obtained from $\mathrm{HCl}$ solution (i.e., $\mathrm{CA} \cdot \mathrm{M} \cdot 3 \mathrm{HCl}$ ), and revealed a onedimensional linear tape structure. Later, Ranganathan et al. [14] reported the crystal structure of M/CA adducts obtained by hydrothermal synthesis. This latter structure confirmed the expected rosette-type structures, which form a hexagonal 
network arranged through hydrogen bonds (HBs). The molecular structure has also revealed that two additional aggregates can occur: infinite linear tapes and infinite crinkled tapes. However, the M/CA crystal structure was recently more accurately redetermined by Prior et al. [15], who gave precise information on the intermolecular distances and stacking interactions.

Several investigations have been attempted with the purpose of understanding the fundamental process of selfassembly between $\mathrm{M}$ and CA. Whitesides and coworkers [16-19] have extensively studied covalently modified, M/ CA structures, obtaining polymeric structures of high molecular weight and with small capsules. Bielejewska et al. [20] have recently developed a thermodynamic model that describes the relative stabilities of various hydrogen-bonded species. They have also performed gas-phase calculations on covalently modified trimolecular complexes, which have shown a relationship between the size of the substituents and the coplanarity of the complexes. The M/CA mixture was also studied on a $\mathrm{Au}(111)$ surface by $\mathrm{Xu}$ et al. [21], in which they found a novel network based on the $\mathrm{M}_{3} / \mathrm{CA}_{1}$ cluster, besides the well-known lattice. Furthermore, Ma and Bong [22] have studied an $\mathrm{M} / \mathrm{CA}$ water mixture, and also a trivalent derivative system in water $[11,22]$ with the aim of examining recognition and assembly processes in aqueous media, research that is still rare.

With the aim of characterizing the noncovalent interactions in $\mathrm{M} / \mathrm{CA}$ clusters and thus shedding more light on the molecular factors that govern the processes of self-assembly and crystal packing, we hereby report electronic structure calculations on a set of 13 hydrogen-bonded complexes of $\mathrm{M}_{n} \mathrm{CA}_{m}$ (with $n, m=1,2,3$ ) taken from crystallographic data as starting points.

\section{Computational details}

We explored two well-known motifs of $\mathrm{M}$ and $\mathrm{CA}$, the cyclic and the linear hydrogen-bonded assemblies. By following the aggregation scheme shown in Fig. 1, we took geometries of $\mathrm{M}_{n} / \mathrm{CA}_{m}$ clusters (from I to XIII; with $n, m=1,2,3$ ) from the crystallographic structure data obtained by Prior et al. [15]. All geometries were fully optimized without any constraint at the B3LYP/6-311++G(d,p) level of theory with use of the Gaussian 03 suite of programs [23]. This functional has shown excellent performance in the calculation of structures [24, 25] and topological properties of hydrogen-bonded complexes [25-28], especially in structures with highly directional interactions $[29,30]$. The minimum energy nature of the optimized structures was verified by vibrational frequency analysis. The binding energies (BEs) were obtained at the same level of theory with the supermolecular approach, and were calculated as the difference between the total energy of the complex and

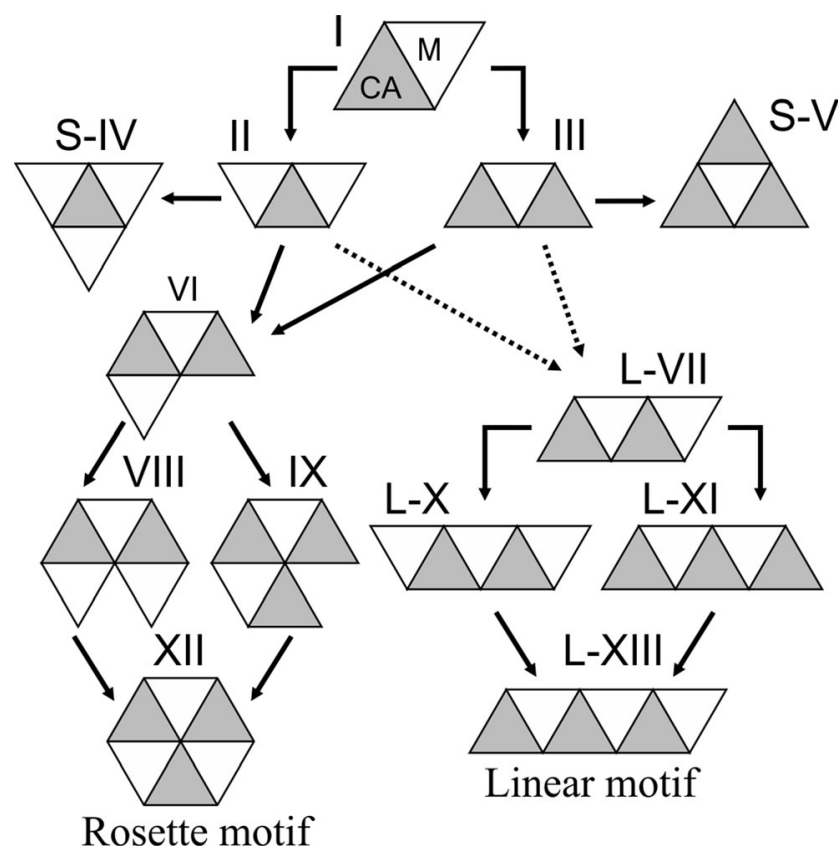

Fig. 1 Different aggregation states: melamine (M)/cyanuric acid (CA) I; $\mathrm{M}_{2} / \mathrm{CA}$ II; M/CA 2 III; $\mathrm{M}_{3} / \mathrm{CA}$ starlike structure $\mathbf{S}-\mathbf{I V} ; \mathrm{M} / \mathrm{CA}_{3}$ starlike structure $\mathbf{S}-\mathbf{V} ; \mathrm{M}_{2} / \mathrm{CA}_{2}$ VI; $\mathrm{M}_{2} / \mathrm{CA}_{2}$ linear type $\mathbf{L}-\mathbf{V I I} ; \mathrm{M}_{3} / \mathrm{CA}_{2}$ VIII $; \mathrm{M}_{2} /$ $\mathrm{CA}_{3} \mathbf{I X} ; \mathrm{M}_{3} / \mathrm{CA}_{2}$ linear type $\mathbf{L}-\mathbf{X} ; \mathrm{M}_{2} / \mathrm{CA}_{3}$ linear type $\mathbf{L}-\mathbf{X I} ; \mathrm{M}_{3} / \mathrm{CA}_{3}$ XII; $\mathrm{M}_{3} / \mathrm{CA}_{3}$ linear type $\mathbf{L}$-XIII

the sum of the total energies of the isolated molecules. BEs were also corrected $\left(\mathrm{BE}_{\mathrm{corr}}\right)$ for the basis set superposition error with the approach of Boys and Bernardi [31]. To assess the importance of long-range interactions, $\omega$-B97XD [32] single-point energy calculations with the $6-311++G(d, p)$ basis set were also performed with the B3LYP geometries, since this functional predicts very well the geometrical parameters of the experimental structure. Interactions were quantitatively evaluated by a topological analysis of the electron charge density in the framework of the quantum theory of atoms in molecules [33] (QTAIM). We performed this analysis with AIMAll [34], using wave functions generated from the B3LYP/6-311++G(d,p) calculations.

We generated electrostatic potential surfaces by mapping the electrostatic potential $V(r)$ at the B3LYP/6-311++G(d,p) level of theory. We considered an electron density isosurface of $\rho(r)=0.001$ au. This contour of the molecular electronic density was suggested by Bader et al. [35] and represents the effective molecular volume.

\section{Results and discussion}

\section{Geometries}

The optimized geometries of the isolated compounds are shown in Fig. 2, and the selected optimized geometrical parameters of the isolated molecules are given in Table 1. As can 

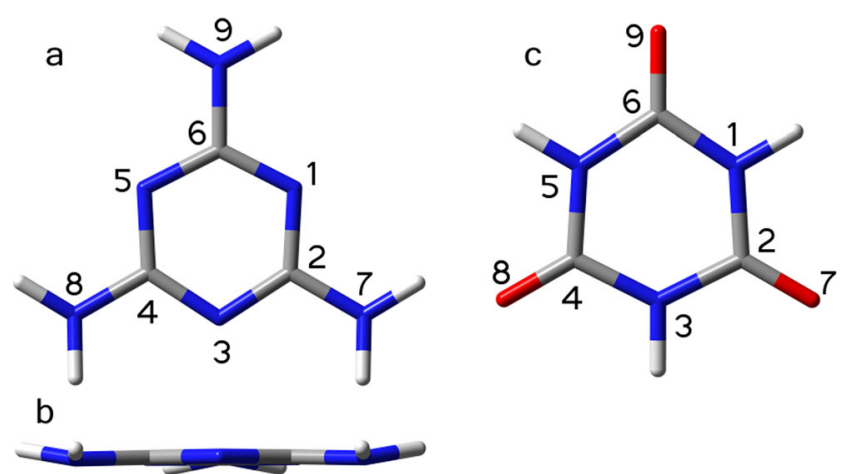

Fig. 2 Optimized geometries of M (a top view; $\mathbf{b}$ side view) and CA (c) at the B3LYP/6-311++G(d,p) level of theory

be seen in Fig. 2a and b, the isolated geometry of M is quasi planar because of the nitrogen inversion. This result is in accordance with the findings of previous experimental and theoretical studies [36-38] that have shown that $\mathrm{M}$ has a structure close in symmetry to $D_{3 \mathrm{~h}}$. Besides, CA is completely planar (Fig. 2c). With regard to geometrical parameters, one can see that the calculated values are in significant agreement with the values obtained from X-ray diffraction, with differences of less than $1 \%$.

All complexes are bound through a set of three HBs, as shown in Fig. 3a; that is, a central interaction, $\mathrm{N}-\mathrm{H} \cdots \mathrm{N}$, in which $\mathrm{CA}$ acts as a proton donor, and two side interactions, $\mathrm{N}-\mathrm{H} \cdots \mathrm{O}$, in which $\mathrm{M}$ acts as a double proton donor. In Fig. 3b it can be seen that the two amino groups of $\mathrm{M}$ are coplanar with the ring, whereas the amino group that does not interact with CA and keeps its quasi-pyramidal form. Nevertheless, on addition of more CA units, all amino groups become planar, suggesting that conformational changes occur on HB formation. Table 2 reports the values of the main parameters that describe the geometry of the M/CA complex (I). These

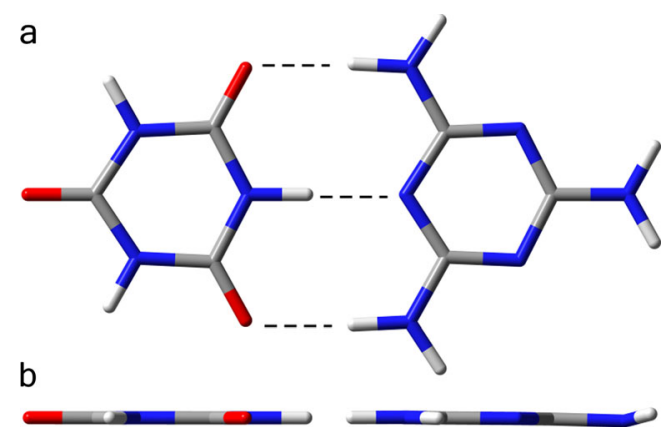

Fig. 3 Optimized geometry of the M/CA complex at the B3LYP/6$311++\mathrm{G}(\mathrm{d}, \mathrm{p})$ level of theory; $\mathbf{a}$ top view and $\mathbf{b}$ side view

parameters are the $\mathrm{H} \cdots \mathrm{A}$ intermolecular distance (where A is $\mathrm{N}, \mathrm{O}$ ), the $\mathrm{N}-\mathrm{H}$ bond length, and the $\mathrm{N}-\mathrm{H} \cdots \mathrm{A}$ equilibrium angle $\alpha . \Delta d_{\mathrm{VdW}}(\mathrm{H} \cdots \mathrm{A})$ represents the difference between the sum of the van der Waals radii of $A$ and $H$ atoms [39] and the $\mathrm{H} \cdots \mathrm{A}$ intermolecular distances, and $\Delta d(\mathrm{D}-\mathrm{X})$ represents the variation in the bond donor distance on complexation; that is, the difference between the distance $d(\mathrm{D}-\mathrm{X})$ in the complexes and in the isolated monomers. It is important to note that the calculated values in Tables 1 and 2 are in good agreement with the values obtained from X-ray diffraction; the relative difference between these quantities is less than $2 \%$. This confirms that the B3LYP/6-311++G(d,p) level of approximation is suitable for the compounds studied here and reflects the environment of the crystal structure.

In all cases the $\mathrm{H}^{\cdots} \mathrm{A}$ intermolecular distances are substantially shorter than the sum of the van der Waals radii of the $\mathrm{H}$ and $\mathrm{A}$ atoms. Positive values of $\Delta d_{\mathrm{VdW}}(\mathrm{H} \cdots \mathrm{A})$ can be taken as the distance of penetration of electronic densities of atoms $\mathrm{H}$ and $\mathrm{A}$. From analysis of the $\mathrm{N} \cdots \mathrm{N}$ and $\mathrm{N} \cdots \mathrm{O}$ distances versus the number of molecular units for all complexes (see Fig. S1, Table S1), it can be clearly seen that all $\mathrm{N} \cdots \mathrm{N}$
Table 1 Selected geometric parameters of melamine $(M)$ and cyanuric acid $(C A)$ compounds calculated at the B3LYP/6-311++ $\mathrm{G}(\mathrm{d}, \mathrm{p})$ level of theory, together with X-ray parameters

\begin{tabular}{|c|c|c|c|c|c|}
\hline \multicolumn{3}{|l|}{ M } & \multicolumn{3}{|l|}{$\mathrm{CA}$} \\
\hline Atoms & B3LYP & $X$-ray ${ }^{a}$ & Atoms & B3LYP & X-ray ${ }^{a}$ \\
\hline \multicolumn{6}{|l|}{ Distances $(\AA)$} \\
\hline $\mathrm{C} 2-\mathrm{N} 7$ & 1.3399 & 1.3244 & $\mathrm{C} 2-\mathrm{O} 7$ & 1.2254 & 1.2320 \\
\hline $\mathrm{C} 4-\mathrm{N} 8$ & 1.3399 & 1.3300 & $\mathrm{C} 4-\mathrm{O} 8$ & 1.2253 & 1.2354 \\
\hline C6-N9 & 1.3399 & & $\mathrm{C} 6-\mathrm{O} 9$ & 1.2254 & \\
\hline N5-C6 & 1.3511 & 1.3562 & $\mathrm{~N} 1-\mathrm{C} 2$ & 1.3771 & 1.3746 \\
\hline $\mathrm{N} 3-\mathrm{C} 2$ & 1.3511 & 1.3600 & N3-C4 & 1.3770 & 1.3708 \\
\hline N5-C4 & 1.3511 & 1.3575 & $\mathrm{C} 4-\mathrm{N} 5$ & 1.3771 & 1.3746 \\
\hline \multicolumn{6}{|l|}{ Angles $\left({ }^{\circ}\right)$} \\
\hline N5-C6-N1 & 124.51 & 124.82 & $\mathrm{~N} 1-\mathrm{C} 2-\mathrm{N} 3$ & 115.82 & 115.92 \\
\hline C6-N1-C2 & 115.50 & 115.35 & C4-N5-C6 & 124.19 & 123.58 \\
\hline $\mathrm{C} 2-\mathrm{N} 3-\mathrm{C} 4$ & 115.51 & 115.69 & N5-C6-N1 & 115.81 & 116.26 \\
\hline N3-C4-N5 & 124.50 & 124.35 & C6-N1-C2 & 124.19 & 123.97 \\
\hline
\end{tabular}

${ }^{\mathrm{a}}$ Experimental values obtained by Prior et al. [15] 
Table 2 Selected geometric parameters of complex I calculated at the B3LYP/6-311++ $\mathrm{G}(\mathrm{d}, \mathrm{p})$ level of theory

\begin{tabular}{lllllll}
\hline Interaction & $d(\mathrm{~N} \cdots \mathrm{A})$ & $d(\mathrm{H} \cdots \mathrm{A})$ & $\Delta d_{\mathrm{VdW}}(\mathrm{H} \cdots \mathrm{A})^{\mathrm{a}}$ & $d(\mathrm{~N}-\mathrm{H})$ & $\Delta d(\mathrm{~N}-\mathrm{H})$ & $\alpha(\mathrm{N}-\mathrm{H} \cdots \mathrm{N})$ \\
\hline $\mathrm{N}-\mathrm{H} \cdots \mathrm{N}$ & 2.856 & 1.798 & 0.952 & 1.059 & 0.048 & 179.99 \\
& $(2.861)^{\mathrm{b}}$ & $(1.93)^{\mathrm{b}}$ & & $(0.930)^{\mathrm{b}}$ & & $(180.00)^{\mathrm{b}}$ \\
& $(2.850-2.880)^{\mathrm{c}}$ & & & & & \\
$\mathrm{N}-\mathrm{H} \cdots \mathrm{O}$ & 2.984 & 1.970 & 0.750 & 1.013 & 0.008 & 174.86 \\
& $(2.938)^{\mathrm{b}}$ & $(2.07)^{\mathrm{b}}$ & & $(0.880)^{\mathrm{b}}$ & & $(177.70)^{\mathrm{b}}$ \\
& $(2.940-2.980)^{\mathrm{c}}$ & & & & \\
$\mathrm{N}-\mathrm{H} \cdots \mathrm{O}$ & 2.984 & 1.970 & 0.750 & 1.013 & 0.008 & 174.85 \\
& $(2.947)^{\mathrm{b}}$ & $(2.08)^{\mathrm{b}}$ & & $(0.870)^{\mathrm{b}}$ & & $(174.80)^{\mathrm{b}}$ \\
\hline
\end{tabular}

Distances are in angstroms and angles are in degrees. Values in parentheses correspond to the structures obtained by X-ray diffraction.

${ }^{\text {a }} \Delta d_{\mathrm{VdW}}(\mathrm{H} \cdots \mathrm{A})$ is the difference between the equilibrium intermolecular distances and the sum of the van der Waals radii of $\mathrm{H}$ and $\mathrm{A}$ atoms (van der Waals radii from [39]: $\mathrm{H}, 1.20 \AA ; \mathrm{N}, 1.55 \AA$; and $\mathrm{O}, 1.50 \AA$ )

${ }^{\mathrm{b}}$ Experimental values obtained by Prior et al. [15]

${ }^{\mathrm{c}}$ Experimental values obtained by Ranganatham et al. [14] distances are increased from $2.856 \AA$ in complex I to a maximum mean length of $2.89 \AA$ on our going from complex I to either the rosette motif (XII) or the linear motif (L-XIII). Therefore, these results show typical geometrical characteristics of noncooperative effects $[40,41]$. All the distances are longer than those observed in the crystal except for the $\mathrm{N} \cdots \mathrm{N}$ distance of complex I. With regard to $\mathrm{N}-\mathrm{H} \cdots \mathrm{O}$ interactions, it is evidenced that some $\mathrm{N} \cdots \mathrm{O}$ distances decrease and others increase (i.e., both cooperative and noncooperative effects could be operating at the same time). However, in the set of tetramolecular complexes only structures $\mathbf{S}-\mathbf{I V}$ and $\mathbf{S}-\mathbf{V}$ do not show reduction of $\mathrm{N} \cdots \mathrm{O}$ distances.

On the other hand, all $\Delta d(\mathrm{~N}-\mathrm{H})$ changes are positive; that is, the $\mathrm{N}-\mathrm{H}$ bond stretched as a result of complexation. However, on our going from complex I to L-XIII, the magnitude of the $\mathrm{N}-\mathrm{H}$ bond elongations decreases slightly, again in contrast to the geometrical features of HB cooperativity.

Finally, equilibrium angles reflect the collinearity among all the molecules within each complex. The $\mathrm{N}-\mathrm{H} \cdots \mathrm{N}$ angles range from $180^{\circ}$ (value for complex I) to a mean value of $179^{\circ}$; hence, there is a minor decrease in coplanarity on aggregation. The lowest value is observed in complex L-XIII, the linear analogue of the rosette-type complex. The plane where the molecules are placed is curved, as is shown in Fig. 4. With regard to side interactions, being less collinear than the central interaction, the $\mathrm{N}-\mathrm{H} \cdots \mathrm{O}$ angles range from $175^{\circ}$ to $178^{\circ}$.

\section{Energetic analysis}

BEs of all the clusters are given in Table 3. We also calculated the $\mathrm{BE}$ per molecular unit added $\left(\mathrm{BE}_{\mathrm{PU}}\right)$ using Eqs. 1 and 2:

$$
\begin{aligned}
& \forall m \geq n ; \quad B E_{P U}=E_{M_{n} / C_{m}}-E_{M_{n-1} / C A_{m}}-E_{M} \\
& \forall n \geq m ; \quad B E_{P U}=E_{M_{n} / C_{m}}-E_{M_{n} / C A_{m-1}}-E_{C A}
\end{aligned}
$$

where $n$ and $m$ are the numbers of molecular entities.

As can be seen from Table 3, the corrected energy differences separating the group of complexes (bimolecular, trimolecular, tetramolecular, and pentamolecular complexes) are very small. Therefore, it is hazardous to draw conclusions about relative stabilities and establish the most energetically favored agreggation path. Nevertheless, the BEs increase in the following order for both functionals: II $<$ III, S-IV $<$ S-V $<$ LVII $<$ VI, L-XI $<$ IX $<$ L-X $<$ VIII, L-XIII $<$ XII. A clear separation of BEs occurs between complexes XII and L-XIII, with a difference of $14 \mathrm{kcal} / \mathrm{mol}$ for the B3LYP functional and almost $19 \mathrm{kcal} / \mathrm{mol}$ for the $\omega$-B97XD functional. This is because completion of the ring in complexes VIII and IX generates three additional HBs in comparison with the linear hexamer.

Despite some HBs seeming to be cooperative, as was seen in "Geometries," it is worth stressing that the results obtained by Eqs. 1 and 2 show that the mean effect is a negative cooperativity in all complexes. That is, in all cases the total interaction energy is less than the sum of the $\mathrm{BE}$ of complex $\mathbf{I}$ (e.g., $\mathrm{BE}_{\mathbf{I I}}<\mathrm{BE}_{\mathbf{I}} \times 2$ and $\mathrm{BE}_{\mathbf{I I I}}<\mathrm{BE}_{\mathbf{I}} \times 2$ ). In other words, the whole is not greater than the sum of the parts.

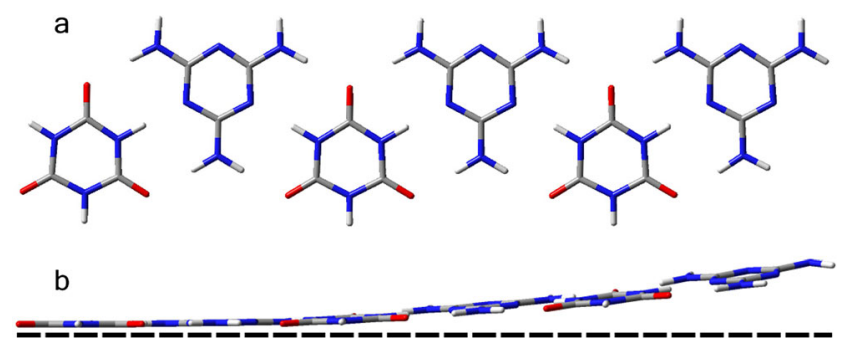

Fig. 4 Optimized geometry of complex L-XIII at the B3LYP/6-311++ $\mathrm{G}(\mathrm{d}, \mathrm{p})$ level of theory: a top view and $\mathbf{b}$ side view. The dashed line serves as a reference 
Table 3 Corrected binding energies $(\mathrm{kcal} / \mathrm{mol})$ calculated at the B3LYP/6 $-311++\mathrm{G}(\mathrm{d}, \mathrm{p})^{\mathrm{b}}$ and $\omega-\mathrm{B} 97 \mathrm{XD} / 6-311++\mathrm{G} * * / /$ B3LYP/6-311++G** levels of theory

\begin{tabular}{|c|c|c|c|c|c|}
\hline \multirow[t]{2}{*}{ Complex } & & \multirow[t]{2}{*}{ B3LYP BE } & \multicolumn{2}{|l|}{$\mathrm{BE}_{\mathrm{PU}}$} & \multirow[t]{2}{*}{$\omega-B 97 X D$ BE } \\
\hline & & & $m \geq n$ & $m \leq n$ & \\
\hline I & $\mathrm{M} / \mathrm{CA}$ & -15.26 & - & - & -19.33 \\
\hline II & $\mathrm{M}_{2} / \mathrm{CA}$ & -30.04 & -15.61 & - & -38.25 \\
\hline III & $\mathrm{M} / \mathrm{CA}_{2}$ & -29.83 & - & -15.36 & -37.98 \\
\hline S-IV & $\mathrm{M}_{3} / \mathrm{CA}$ & -44.34 & -15.16 & - & -56.92 \\
\hline S-V & $\mathrm{M} / \mathrm{CA}_{3}$ & -43.55 & - & -14.55 & -55.87 \\
\hline VI & $\mathrm{M}_{2} / \mathrm{CA}_{2}$ & -44.82 & -15.60 & -15.85 & -57.14 \\
\hline L-VII & $\mathrm{M}_{2} / \mathrm{CA}_{2}$ & -44.59 & -15.60 & -15.35 & -56.93 \\
\hline VIII & $\mathrm{M}_{3} / \mathrm{CA}_{2}$ & -59.40 & -15.45 & - & -76.07 \\
\hline IX & $\mathrm{M}_{2} / \mathrm{CA}_{3}$ & -59.24 & - & -15.24 & -75.72 \\
\hline L-X & $\mathrm{L}-\mathrm{M}_{3} / \mathrm{CA}_{2}$ & -59.39 & -15.64 & - & -75.85 \\
\hline L-XI & $\mathrm{L}-\mathrm{M}_{2} / \mathrm{CA}_{3}$ & -59.18 & - & -15.39 & -75.51 \\
\hline XII & $\mathrm{M}_{3} / \mathrm{CA}_{3}$ & -88.37 & -30.95 & -30.74 & -113.33 \\
\hline L-XIII & $\mathrm{L}-\mathrm{M}_{3} / \mathrm{CA}_{3}$ & -73.94 & -15.49 & -15.29 & -94.57 \\
\hline
\end{tabular}

$B E$ binding energy, $B E_{\mathrm{PU}}$ binding energy per molecular unit added

\section{Topology of the electron density}

We addressed the nature of the HBs by analyzing the electron density distribution within the QTAIM [33]. Different bond properties were used to analyze the nature of the interactions that occur in the different complexes: the electron charge density $\rho\left(r_{\mathrm{c}}\right)$, which measures the accumulation of charge between the bonded nuclei and reflects the bond strength [42, $43]$; the Laplacian of the electron density $\nabla^{2} \rho\left(r_{\mathrm{c}}\right)$, which provides information on the local charge concentration $\left(\nabla^{2} \rho\left(r_{\mathrm{c}}\right)<0\right)$ or depletion $\left(\nabla^{2} \rho\left(r_{\mathrm{c}}\right)>0\right)$; the kinetic energy densities $G\left(r_{\mathrm{c}}\right)$, the potential energy densities $V\left(r_{\mathrm{c}}\right)$; and the total electronic energy density $H\left(r_{\mathrm{c}}\right)=V\left(r_{\mathrm{c}}\right)+G\left(r_{\mathrm{c}}\right)$.

The molecular graphs of all the complexes are displayed in Fig. 5, and the local properties calculated at bond critical points (BCPs) are given in Table S2. The topological properties at each BCP fall within the proposed range used to characterize HB formation [44]. The charge density values lie in the range from 0.02 to $0.05 \mathrm{au}$. The Laplacian values in all complexes are positive and lie in the range from 0.08 to $0.1 \mathrm{au}$.

It has been shown that $\rho\left(r_{\mathrm{c}}\right)$ is a good indicator of the bond order and the bond strength [43]. Thus, the increase or decrease of this property can be related to the cooperativity or negative cooperativity of HBs respectively $[45,46]$. In complex I (Fig. 5), the $\mathrm{N}-\mathrm{H} \cdots \mathrm{N}$ interaction is nearly two times stronger than the $\mathrm{N}-\mathrm{H} \cdots \mathrm{O}$ interaction, as the values of $\rho\left(r_{\mathrm{c}}\right)$ show. Figure 5 also indicates the increase (green arrows) or decrease (red arrows) of $\rho\left(r_{\mathrm{c}}\right)$ at BCPs with respect to complex I. In complexes II and III, two $\mathrm{N}-\mathrm{H} \cdots \mathrm{O}$ interactions undergo an increase in the charge density, by $0.95 \%$ in complex II and by $2.39 \%$ in complex III. However, complex III experiences a greater decrease of density in the remaining interactions (red arrows in Fig. 5) with respect to complex II, which explains the greater $\mathrm{BE}$ in the latter.

In tetramolecular complexes, starlike topologies show different behaviors. With regard to complex $\mathbf{S}-\mathbf{I V}$, surprisingly all $\mathrm{N}-\mathrm{H} \cdots \mathrm{O}$ interactions show an increase of charge density, in contrast to the geometrical results in "Geometries," which indicate typical characteristics of noncooperative effects. In contrast, complex $\mathbf{S}-\mathbf{V}$ exhibits a decrease of charge density at all BCPs. That complex $\mathbf{S - I V}$ is energetically and topologically favored over complex $\mathbf{S}-\mathbf{V}$ supports previous research by $\mathrm{Xu}$ et al. [21]. They reported a novel phase of $\mathrm{M} / \mathrm{CA}$ adsorbed on a $\mathrm{Au}(111)$ surface with an M-to-CA ratio of $3: 1$, which is the equivalent of complex $\mathbf{S}-\mathbf{I V}$, instead of the well-known 1:1 ratio found in the co-crystal. Complex VI shows an increase of charge density in $\mathrm{N}-\mathrm{H} \cdots \mathrm{O}$ interactions of the outer edge (see Fig. 5), whereas the remaining interactions show a decrease of this property. The linear analogue, complex L-VII, shows an increase of $\rho\left(r_{\mathrm{c}}\right)$ on one side of the complex (see Fig. 5). A comparison between complexes VI and L-VII reveals that major decreases of $\rho\left(r_{\mathrm{c}}\right)$ occurs in the linear complex, in accordance with a greater BE in complex VI.

Pentamolecular complexes require special attention, as interesting topological characteristics arise. With respect to cyclic assemblies, an increase of the charge density in $\mathrm{N}-\mathrm{H} \cdots \mathrm{O}$ interactions of the outer edge is observed. Furthermore, in complex VIII a so-called dihydrogen bond, $\mathrm{H} \cdots \mathrm{H}$, occurs. This interaction was characterized for the first time, within the QTAIM, by Popelier [47], who has verified the eight criteria used to describe HBs [44]. Our results show deviations from these criteria, since $\rho\left(r_{\mathrm{c}}\right)$ at the BCP $(0.000106 \mathrm{au})$ does not fall within the proposed range of $0.002-0.035$ au [44]. Therefore, this interaction can be classified as a van der 

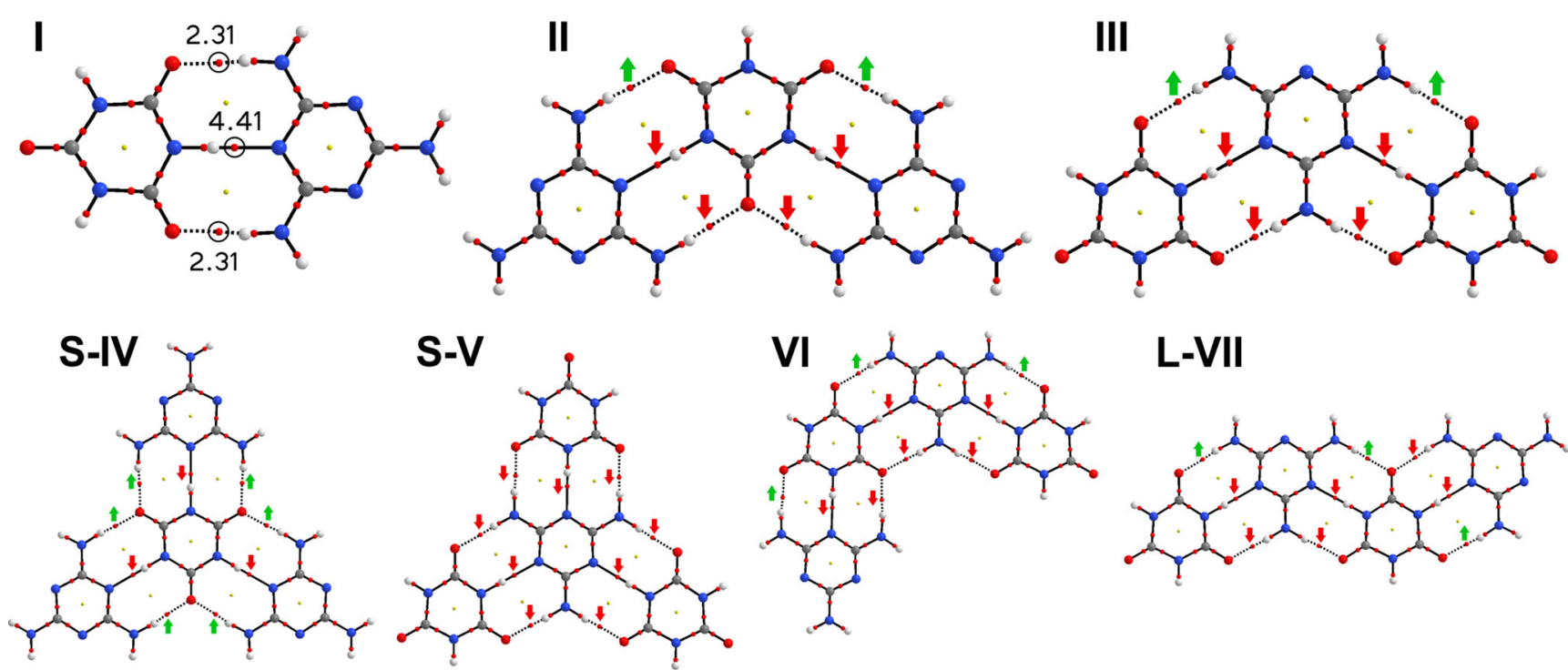

L-VII

VIII

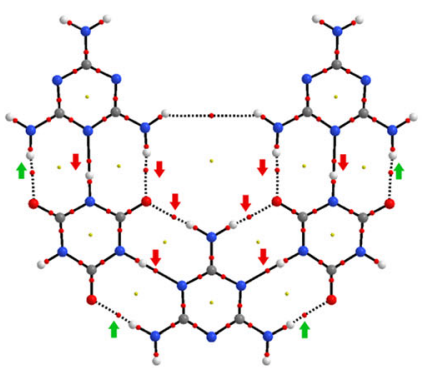

L-X

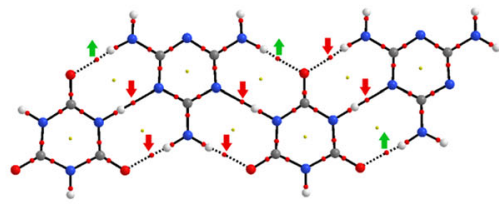

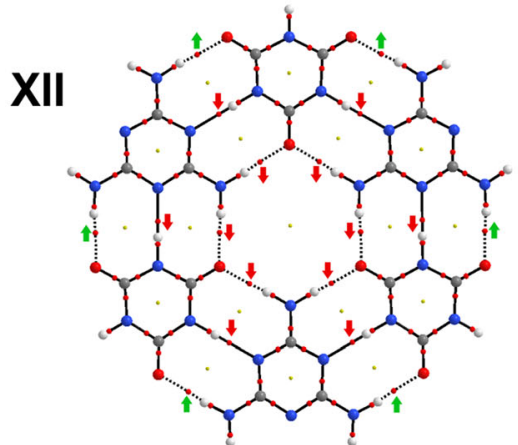

Fig. 5 Molecular graphs of the complexes. Values of $\rho\left(r_{\mathrm{c}}\right)$ at bond critical points (BCPs) are reported in units of $10^{-3}$ au. Green arrows and red arrows indicate increase and decrease respectively of $\rho\left(r_{\mathrm{c}}\right)$ at BCPs.

Waals type since the QTAIM parameters fulfill the criteria of closed-shell interactions: the value of $\rho\left(r_{\mathrm{c}}\right)$ is relatively low; the ratio of the perpendicular contraction of $\rho\left(\lambda_{1}\right)$ to its parallel expansion $\left(\lambda_{3}\right),\left|\lambda_{1}\right| / \lambda_{3}$, is less than 1 ; and $\nabla^{2} \rho\left(r_{\mathrm{c}}\right)>0$ [33]. In concert with complex IX, a BCP between two $\mathrm{O}$ atoms $(\mathrm{O} \cdots \mathrm{O})$ occurs with a density of $0,000028 \mathrm{au}$, which can also be classified as a van der Waals interaction. Since complex VIII is more stable than complex IX by $0.21 \mathrm{kcal} / \mathrm{mol}$, a good indicator of structural stability is the distance between a BCP and a ring critical point (RCP). If these critical points are joined, the ring tends to open because of a bond rupture [47]. In complex
The lines connecting the nuclei are the bond paths. Small red dots and small yellow dots represent BCPs $(3,-1)$ and ring critical points $(3,+1)$ respectively

VIII, the distance between the $\mathrm{H} \cdots \mathrm{H}$ BCP and the nearest RCP is $1.822 \AA$, whereas in complex IX, the distance between the $\mathrm{O} \cdots \mathrm{O} \mathrm{BCP}$ and its nearest $\mathrm{RCP}$ is $1.528 \AA$; therefore, the former is more stable, in line with the BEs.

Unlike the cyclic pentamolecular complexes, the linear structures (L-X and $\mathbf{L}-\mathbf{X I}$ ) show different topological patterns as shown in Fig. 5. In complex $\mathbf{L}-\mathbf{X}$, the reinforced interactions (green arrows) alternate from side to side, whereas in complex L-XI, they occur on one side of the complex. It is worth stressing that the linear complex $\mathbf{L}-\mathbf{X}$ is more stable than the cyclic one by $0.14 \mathrm{kcal} / \mathrm{mol}$. This 


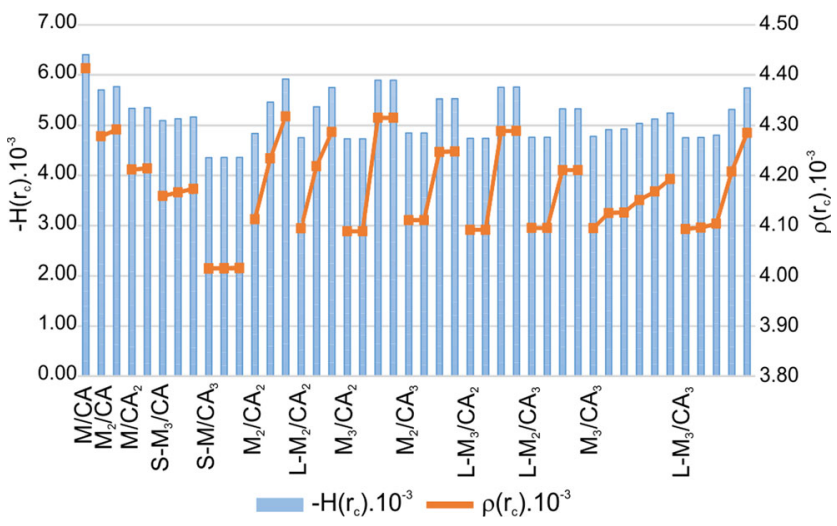

Fig. $6-H\left(r_{\mathrm{c}}\right) \times 10^{-3}$ and $\rho\left(r_{\mathrm{c}}\right) \times 10^{-3}$ at $\mathrm{N}-\mathrm{H}^{\cdots} \mathrm{N}$ BCPs for complexes I to XIII

small difference could be attributed to the $\mathrm{O} \cdots \mathrm{O}$ interaction in complex IX that adds some steric stress. As expected, an increase in the stability of the cyclic rosette complex (complex XII) is produced by the formation of three additional HBs, which forms a new RCP. This arrangement is driven by the enhanced interactions (positive cooperativity) that occur in the outer region of the complex; thus forming a ring of cooperativity.

Besides $\rho\left(r_{\mathrm{c}}\right)$, another property that could be considered as an indicator of the strength of interactions is the value and the sign of the total electronic energy density $[46,48,49] H\left(r_{\mathrm{c}}\right)$, which has also been associated with the covalent character of a bond when this property takes negative values [50]. All N$\mathrm{H} \cdots \mathrm{N}$ interactions have a negative value of $H\left(r_{\mathrm{c}}\right)$, whereas $\mathrm{N}-$ $\mathrm{H} \cdots \mathrm{O}$ interactions have a positive value. This indicates that the $\mathrm{N}-\mathrm{H} \cdots \mathrm{N}$ interaction is much stronger than the $\mathrm{N}-\mathrm{H} \cdots \mathrm{O}$ interaction. Figure 6 clearly reveals how these two properties vary with the cluster size. The lowest value of $H\left(r_{\mathrm{c}}\right)$ and the highest value of $\rho\left(r_{\mathrm{c}}\right)$ are reached in the adduct. Whereas $\rho\left(r_{\mathrm{c}}\right)$ decreases as the cluster size increases, $H\left(r_{\mathrm{c}}\right)$ becomes less negative, indicating a weakening of $\mathrm{N}-\mathrm{H} \cdots \mathrm{N}$ interactions and, in other words, a negative cooperativity.

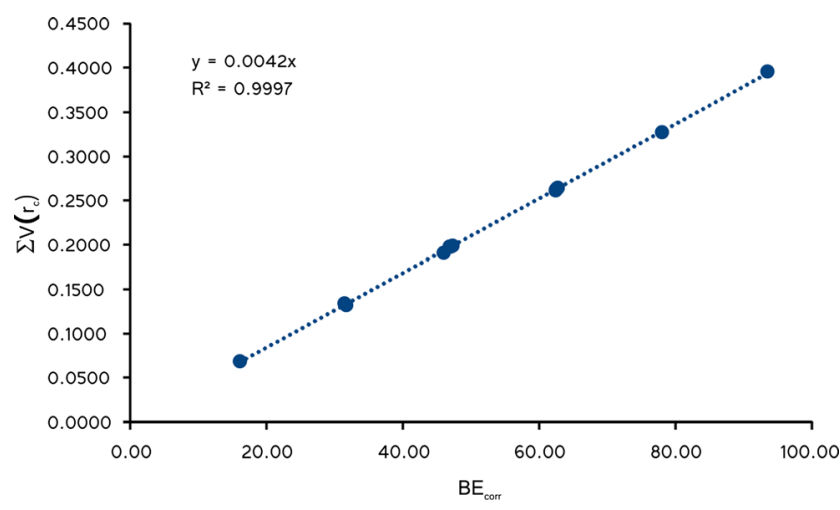

Fig. 8 Relationship between absolute values of $\Sigma V\left(r_{\mathrm{c}}\right)$ at all hydrogenbond $\mathrm{BCPs}$ and binding energies. $B E_{\text {corr }}$ corrected binding energy

Figure 7 shows the variations of $H\left(r_{\mathrm{c}}\right)$ and $\rho\left(r_{\mathrm{c}}\right)$ at $\mathrm{N}-\mathrm{H} \cdots \mathrm{O}$ BCPs. Since $H\left(r_{\mathrm{c}}\right)$ accounts for contributions from both kinetic and potential energy densities, the stablest complexes are those with smaller $H\left(r_{\mathrm{c}}\right)$ values (less positive) - that is, complexes with a greater potential energy density - and $V\left(r_{\mathrm{c}}\right)$ represents the capacity to concentrate electrons at BCPs. From Fig. 7 it can be immediately seen that the electron density increases (above the dashed line) and decreases within each complex, in line with variations of $\mathrm{N} \cdots \mathrm{O}$ distances. In general, it can be observed that as $\mathrm{N} \cdots \mathrm{O}$ lengths decrease, $\rho\left(r_{\mathrm{c}}\right)$ values increase. Nevertheless, despite the increase of the $\mathrm{N} \cdots \mathrm{O}$ lengths in complex S-IV $\left(\mathrm{M}_{3} \mathrm{CA}\right)$ with respect to complex I (M/CA), the magnitude of $\rho\left(r_{\mathrm{c}}\right)$ increases and $H\left(r_{\mathrm{c}}\right)$ decreases, indicating an enhancement of $\mathrm{N}-\mathrm{H} \cdots \mathrm{O}$ interactions.

Finally, the relationship between the local electronic potential energy density, $V\left(r_{\mathrm{c}}\right)$, and the BE was evaluated, since Espinosa et al. [51] have shown that $V\left(r_{\mathrm{c}}\right)$ is a good parameter that reflects the strength of $\mathrm{HBs}$ [52] (involving $\mathrm{X}-\mathrm{H} \cdots \mathrm{O}$ HBs, where $X$ is $C, N, O)$. Figure 8 shows the linear fitting between $\Sigma V\left(r_{\mathrm{c}}\right)$ at all HBs and BEs for all clusters. These results show an excellent linear correlation, as evidenced in
Fig. $7 H\left(r_{\mathrm{c}}\right) \times 10^{-3}$ and

$\rho\left(r_{\mathrm{c}}\right) \times 10^{-3}$ at $\mathrm{N}-\mathrm{H} \cdots \mathrm{O}$ BCPs for complexes I to XIII. The dashed line represents the $\rho\left(r_{\mathrm{c}}\right)$ value of complex I as a reference

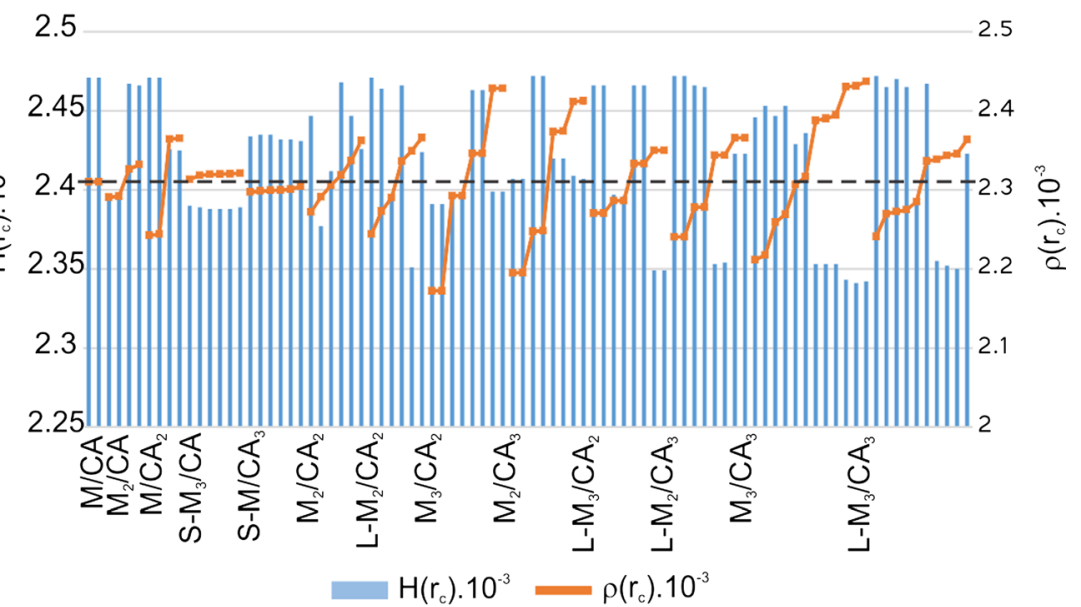


the value of the correlation coefficient. Therefore, we consider that this method is suitable to quantify the contribution of individual interactions to the total BE. Considering that $\rho\left(r_{\mathrm{c}}\right)$ gives an indication of $\mathrm{HB}$ strength, a good linear correlation between this property and the $\mathrm{BE}$ was also evidenced, with $R^{2}=0.9999$.

\section{Molecular electrostatic potential maps}

A very useful topographical analysis is the study of the molecular electrostatic potential (MEP). MEP maps allow one to study noncovalent interactions and to how discover how the electronic charge is distributed within a complex. The electrostatic behaviors of the M/CA adduct and the isolated molecules were analyzed by this method.

The MEP maps of the CA and M isolated compounds and the corresponding M/CA adduct are shown in Fig. 9. As expected, the most negative electrostatic potentials of CA (Fig. 9a) lie on the oxygen atoms, associated with its lone pairs. It can also be seen that the central region of the molecule has a positive electrostatic potential. For the M molecule (see Fig. 9b), since the amino groups have a pyramidal conformation (two up and one down), the molecular plane displays an anisotropic distribution of the electronic charge. Unlike CA, the $\mathrm{M}$ ring has a less positive $V(r)$ on the central region, due to the $\pi$-electron delocalization on the $\mathrm{M}$ ring.

When the $\mathrm{M} / \mathrm{CA}$ adduct is formed, $\mathrm{M}$ undergoes a redistribution of the electronic charge. Comparison of Fig. 9b with Fig. 9c shows this. As can be seen in Fig. 9c, all amino groups exhibit a negative region. The $-\mathrm{NH}_{2}$ group that does not interact with CA exhibits a more negative region on one side of the complex, according to the orientation of the nitrogen lone pair. The remaining $-\mathrm{NH}_{2}$ groups display the same $V(r)$ on both sides of the molecular plane. In addition, a look at the contact limit between $\mathrm{M}$ and $\mathrm{CA}$ shows how the electronic charge is distributed because of the interactions.

Finally, when all $-\mathrm{NH}_{2}$ groups are interacting with at least one CA molecule, they display almost the same charge

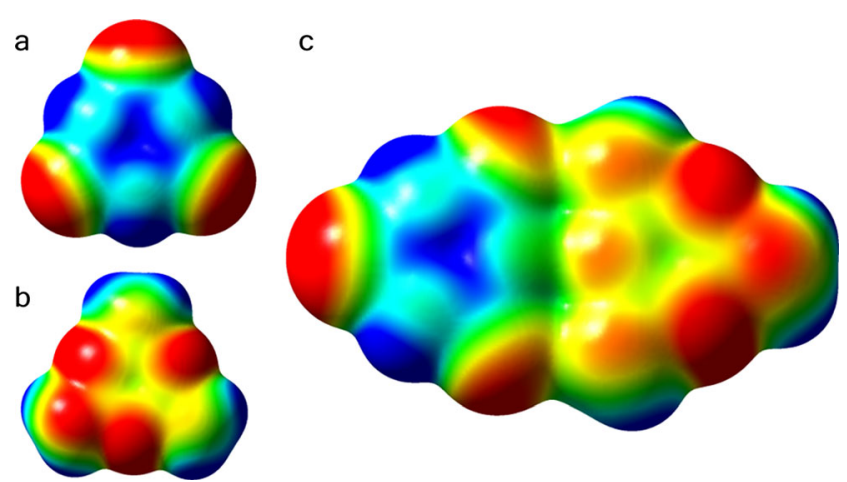

Fig. 9 Molecular electrostatic potential maps of a CA, b M, and $\mathbf{c}$ the M/ $\mathrm{CA}$ complex. Molecular electrostatic potentials range between $-0.027 \mathrm{au}$ (red) and $0.044 \mathrm{au}$ (blue) distribution above and below the molecular plane. This indicates that nitrogen lone pairs delocalized over the entire molecule, and the central region of $\mathrm{M}$ takes more positive values.

\section{Conclusions}

In this work, a theoretical study at the B3LYP/6-311++G(d,p) level of theory in conjunction with QTAIM and MEP analysis was conducted on a series of M/CA clusters taken from crystallographic data so as to characterize the self-assembling interactions and explore the molecular factors that govern the self-assembly process of this system.

The BEs explain the stability of the different aggregates. The cyclization process is favored over linear aggregation. In these cyclic motifs, the outer HBs are strengthened, whereas the inner ones are weakened with respect to the primitive complex (i.e., the $\mathrm{M} / \mathrm{CA}$ adduct).

The geometrical and topological parameters suggest that the fundamental process of M/CA self-assembly is driven by a hydrogen-bonded network that is governed by a complex combination of cooperative and anticooperative effects. The topological properties at BCPs also give detailed insight into the strength of the intermolecular interactions involved in the cluster formation. In addition, the $\mathrm{N}-\mathrm{H} \cdots \mathrm{N}$ interaction is far stronger than the $\mathrm{N}-\mathrm{H} \cdots \mathrm{O}$ HBs, since the former shows negative values of the total electronic energy density at the BCP, which is associated with a greater stabilization.

It is thought that these findings will serve to complement kinetic and thermodynamic considerations involved in the study of self-assembly systems. Our theoretical results support the experimental finding of a novel $\mathrm{M}_{3} / \mathrm{CA}$ (3:1) network, which was found in adsorption experiments, besides the well-known $\mathrm{M}_{3} / \mathrm{CA}_{3}$ (1:1) hydrogen-bonding network of the co-crystal.

Acknowledgments Grants from Secretaría de Ciencia y Tecnología, Universidad Tecnológica Nacional, Facultad Regional Resistencia supported this work. A.N.P. thanks Consejo Nacional de Investigaciones Científicas y Técnicas (CONICET), Argentina, for a doctoral fellowship. N.M.P. is a CONICET career researcher.

\section{References}

1. Seto CT, Whitesides GM (1993) Molecular self-assembly through hydrogen bonding: supramolecular aggregates based on the cyanuric acid-melamine lattice. J Am Chem Soc 115:905-916

2. Lindsey JS (1991) Self-assembly in synthetic routes to molecular devices. Biological principles and chemical perspectives: a review. New J Chem 15:153-180

3. Lehn J-M (2002) Toward complex matter: supramolecular chemistry and self-organization. Proc Natl Acad Sci U S A 99:4763-4768. doi:10.1073/pnas.072065599 
4. Lehn J-M (1988) Supramolecular chemistry-scope and perspectives molecules, supermolecules, and molecular devices (Nobel Lecture). Angew Chem Int Ed Engl 27:89-112. doi:10.1002 /anie. 198800891

5. Manzano BR, Jalón FA, Soriano ML et al (2008) Multiple hydrogen bonds in the self-assembly of aminotriazine and glutarimide. Decisive role of the triazine substituents. Cryst Growth Des 8: 1585-1594. doi:10.1021/cg7008682

6. Corradi E, Meille S, Messina M et al (2000) Halogen bonding versus hydrogen bonding in driving self-assembly processes. Angew Chem Int Ed 39:1782-1786. doi:10.1002/(SICI)15213773(20000515)39:10<1782::AID-ANIE1782>3.0.CO;2-5

7. Stupp SI, Palmer LC (2014) Supramolecular chemistry and selfassembly in organic materials design. Chem Mater 26:507-518

8. Choi IS, Li X, Simanek EE et al (1999) Self-assembly of hydrogenbonded polymeric rods based on the cyanuric acid $\cdot$ melamine lattice. Chem Mater 11:684-690. doi:10.1021/cm980540j

9. Kerckhoffs JMCA, ten Cate MGJ, Mateos-Timoneda MA et al (2005) Selective self-organization of guest molecules in selfassembled molecular boxes. J Am Chem Soc 127:12697-12708. doi: $10.1021 / \mathrm{ja} 0536973$

10. Kimizuka N, Kawasaki T, Hirata K, Kunitake T (1998) Supramolecular membranes. Spontaneous assembly of aqueous bilayer membrane via formation of hydrogen bonded pairs of melamine and cyanuric acid derivatives. J Am Chem Soc 120:4094 4104

11. Ma M, Gong Y, Bong D (2009) Lipid membrane adhesion and fusion driven by designed, minimally multivalent hydrogenbonding lipids. J Am Chem Soc 131:16919-16926

12. Yagai S, Nakajima T, Karatsu T et al (2004) Phototriggered selfassembly of hydrogen-bonded rosette. J Am Chem Soc 126:1150011508. doi:10.1021/ja047783z

13. Wang Y, Wei B, Wang Q (1990) Crystal structure of melamine cyanuric acid complex $(1: 1)$ trihydrochloride, MCA $\cdot 3 \mathrm{HCl}$. J Crystallogr Spectrosc Res 20:79-84

14. Ranganathan A, Pedireddi VR, Rao CNR (1999) Hydrothermal synthesis of organic channel structures: 1:1 hydrogen-bonded adducts of melamine with cyanuric and trithiocyanuric acids. J Am Chem Soc 121:1752-1753

15. Prior TJ, Armstrong JA, Benoit DM, Marshall KL (2013) The structure of the melamine-cyanuric acid co-crystal. CrystEngComm 15:5838-5843. doi:10.1039/c3ce40709h

16. Seto CT, Whitesides GM (1990) Self-assembly based on the cyanuric acid-melamine lattice. J Am Chem Soc 112:6409-6411. doi:10.1021/ja00173a046

17. Zerkowski JA, Seto CT, Whitesides GM (1992) Solid-state structures of rosette and crinkled tape motifs derived from the cyanuric acid melamine lattice. J Am Chem Soc 114:5473-5475. doi:10.1021/ja00039a096

18. Seto CT, Whitesides GM (1993) Synthesis, characterization, and thermodynamic analysis of a $1+1$ self-assembling structure based on the cyanuric acid-melamine lattice. J Am Chem Soc 115:1330 1340. doi:10.1021/ja00057a016

19. Chin DN, Gordon DM, Whitesides GM (1994) Computational simulations of supramolecular hydrogen-bonded aggregates: HubM3, FlexM3, and adamantane-based hubs in chloroform. J Am Chem Soc 116:12033-12044

20. Bielejewska AG, Marjo CE, Prins LJ et al (2001) Thermodynamic stabilities of linear and crinkled tapes and cyclic rosettes in melamine-cyanurate assemblies: a model description. J Am Chem Soc 123:7518-7533

21. Xu W, Dong M, Gersen $\mathrm{H}$ et al (2007) Cyanuric acid and melamine on Au111: structure and energetics of hydrogen-bonded networks. Small 3:854-858. doi:10.1002/smll.200600407

22. Ma M, Bong D (2011) Determinants of cyanuric acid and melamine assembly in water. Langmuir 27:8841-8853. doi:10.1021/la201415d
23. Frisch MJ, Trucks GW, Schlegel HB, Scuseria GE, Robb MA, Cheeseman JR, Montgomery JA Jr, Vreven T, Kudin KN, Burant JC, Millam JM, Iyengar SS, Tomasi J, Barone V, Mennucci B, Cossi M, Scalmani G, Rega N, Petersson GA, Nakatsuji H, Hada M, Ehara M, Toyota K, Fukuda R, Hasegawa J, Ishida M, Nakajima T, Honda Y, Kitao O, Nakai H, Klene M, Li X, Knox JE, Hratchian HP, Cross JB, Bakken V, Adamo C, Jaramillo J, Gomperts R, Stratmann RE, Yazyev O, Austin AJ, Cammi R, Pomelli C, Ochterski JW, Ayala PY, Morokuma K, Voth GA, Salvador P, Dannenberg JJ, Zakrzewski VG, Dapprich S, Daniels AD, Strain MC, Farkas O, Malick DK, Rabuck AD, Raghavachari K, Foresman JB, Ortiz JV, Cui Q, Baboul AG, Clifford S, Cioslowski J, Stefanov BB, Liu G, Liashenko A, Piskorz P, Komaromi I, Martin RL, Fox DJ, Keith T, Al-Laham MA, Peng CY, Nanayakkara A, Challacombe M, Gill PMW, Johnson B, Chen W, Wong MW, Gonzalez C, Pople JA (2004) Gaussian 03, revision D.01. Gaussian, Wallingford

24. Dey R, Bhattacharya B, Mondal P et al (2014) Fabrication of two supramolecular self-assemblies of Mn(II)-dicarboxylates with trans-4,4'-azobispyridine: analysis of H-bonding interactions with Hirshfeld surfaces and DFT calculations. J Mol Struct 1067:64-73. doi:10.1016/j.molstruc.2014.02.059

25. Scheiner $S$ (2015) Dissection of the factors affecting formation of a CH $\cdots \mathrm{O}$ H-bond. A case study. Crystals 5:327-345. doi:10.3390 /cryst5030327

26. Duarte DJR, Sosa GL, Peruchena NM (2013) Nature of halogen bonding. A study based on the topological analysis of the Laplacian of the electron charge density and an energy decomposition analysis. J Mol Model 19:2035-2041. doi:10.1007/s00894-012-1624-8

27. Kirsch P, Tong Q, Untenecker H (2013) Crystal design using multipolar electrostatic interactions: a concept study for organic electronics. Beilstein J Org Chem 9:2367-2373. doi:10.3762 /bjoc. 9.272

28. Angelina EL, Andujar SA, Tosso RD et al (2014) Non-covalent interactions in receptor-ligand complexes. A study based on the electron charge density. J Phys Org Chem 27:128-134. doi: $10.1002 /$ poc. 3250

29. Elango M, Subramanian V, Sathyamurthy N (2008) The selfassembly of metaboric acid molecules into bowls, balls and sheets. J Phys Chem A 112:8107-8115. doi:10.1021/jp8019254

30. Kannappan K, Werblowsky TL, Rim KT et al (2007) An experimental and theoretical study of the formation of nanostructures of self-assembled cyanuric acid through hydrogen bond networks on graphite $\uparrow$. J Phys Chem B 111:6634-6642

31. Boys SF, Bernardi F (1970) The calculation of small molecular interactions by the differences of separate total energies. Some procedures with reduced errors. Mol Phys 19:553-559

32. Chai J-D, Head-Gordon M (2008) Long-range corrected hybrid density functionals with damped atom-atom dispersion corrections. Phys Chem Chem Phys 10:6615-6620

33. Bader RFW (1994) Atoms in molecules: a quantum theory. Clarendon Press, Oxford

34. Keith TA (2012) AIMAll version 12.06.03. TK Gristmill Software, Overland Park. Available from http://aim.tkgristmill.com/

35. Bader RFW, Caroll MT, Cheeseman JR, Chang C (1987) Properties of atoms in molecules: atomic volumes. J Am Chem Soc 109:79687979

36. Wang Y-L, Mebel AM, Wu C-J et al (1997) IR spectroscopy and theoretical vibrational calculation of the melamine molecule. J Chem Soc Faraday Trans 93:3445-3451. doi:10.1039/a701732d

37. Drozd M, Marchewka MK (2005) The structure, vibrational spectra and nonlinear optical properties of neutral melamine and singly, doubly and triply protonated melaminium cations - theoretical studies. J Mol Struct THEOCHEM 716:175-192. doi:10.1016/j. theochem.2004.11.020 
38. Li Z, Chen G, Xu Y et al (2013) Study of the structural and the spectral characteristics of $\left[\mathrm{C}_{3} \mathrm{~N}_{3}\left(\mathrm{NH}_{2}\right)_{3}\right]_{n}(n=1-4)$ clusters. J Phys Chem A 117:12511-12518

39. Bondi A (1964) Van der Waals volumes and radii. J Phys Chem 68: $441-451$

40. Lee HM, Singh NJ, Kim KS (2006) Weak to strong hydrogen bond. In: Grabowski S (ed) Hydrogen bonding - new insights Springer, Dordrecht, pp 149-192

41. Karpfen A (2003) Cooperative effects in hydrogen bonding. In: Prigogine I, Rice SA (eds) Advances in chemical physics, vol 123. Wiley, Hoboken, pp 469-510

42. Bader RFW, Beddall PM (1972) Virial field relationship for molecular charge distributions and the spatial partitioning of molecular properties. J Chem Phys 56:3320. doi:10.1063/1.1677699

43. Ramírez F, Hadad CZ, Guerra D et al (2011) Structural studies of the water pentamer. Chem Phys Lett 507:229-233. doi:10.1016/j. cplett.2011.03.084

44. Koch U, Popelier PLA (1995) Characterization of C-H-O Hydrogen bonds on the basis of the charge density. J Phys Chem 99:9747-9754. doi:10.1021/j100024a016

45. Vallejos MM, Peruchena NM (2012) Preferential formation of the different hydrogen bonds and their effects in tetrahydrofuran and tetrahydropyran microhydrated complexes. J Phys Chem A 116: 4199-4210. doi:10.1021/jp301498n
46. Angelina EL, Peruchena NM (2011) Strength and nature of hydrogen bonding interactions in mono- and di-hydrated formamide complexes. J Phys Chem A 115:4701-4710. doi:10.1021 /jp1105168

47. Popelier PLA (1998) Characterization of a dihydrogen bond on the basis of the electron density. J Phys Chem A 102:1873-1878

48. Angelina EL, Duarte DJR, Peruchena NM (2013) Is the decrease of the total electron energy density a covalence indicator in hydrogen and halogen bonds? J Mol Model 19:2097-2106. doi:10.1007 /s00894-012-1674-y

49. Duarte DJR, Angelina EL, Peruchena NM (2014) Physical meaning of the QTAIM topological parameters in hydrogen bonding. J Mol Model 20:2510. doi:10.1007/s00894-014-2510-3

50. Cremer D, Kraka E (1984) Chemical bonds without bonding electron density? Does the difference electron-density analysis suffice for a description of the chemical bond? Angew Chem Int Ed Engl 23:627-628. doi:10.1002/anie.198406271

51. Espinosa E, Molins E, Lecomte C (1998) Hydrogen bond strengths revealed by topological analyses of experimentally observed electron densities. Chem Phys Lett 285:170-173

52. Ofori A, Suvanto S, Jääskeläinen S et al (2016) Versatile coordination modes in silver-imidazolecarbaldehyde oxime complexes: structural and computational analysis. Cryst Growth Des 16:255264. doi:10.1021/acs.cgd.5b01222 